DOI: https://doi.org/10.18371/fp.1(33).2019.177098

УДК: 339.16.012.23

\title{
МЕТОДИЧНІ ОСОБЛИВОСТІ ОБГРУНТУВАННЯ БАЗОВИХ СТАТИСТИЧНИХ ФУНКЦІЙ
}

\author{
ЗАСЯДЬКО Аліна Анатоліївна \\ д.т.н., професор, ДВНЗ «Університет банківської справи», \\ Черкаський інститут \\ ORCID ID: 0000-0002-1640-7580 \\ e-mail:sagitta@bigmir.net
}

\section{КАСЯРУМ Олег Павлович}

к.фр.-м.н., дочент, ДВНЗ «Університет банківської справи»,

Черкаський інститут

ORCID ID: 0000-0002-6581-7375

e-mail:kasyaroleg@gmail.com

\section{КАСЯРУМ Ярослав Олегович,}

к.n.н., ДВНЗ «Університет банківської справи»,

Черкаський інститут

ORCID ID: 0000-0002-3783-7520

e-mail:kasyayar@gmail.com

\section{ДІДКОВСБКИЙ Руслан Михайлович,}

д.т.н., професор, ДВНЗ «Університет банківської справи»,

Черкаський інститут

ORCID ID: 0000-0002-5166-7564

e-mail:didkow@gmail.com

Анотація. У статті розглянуто питання узагальнення знань здобувачів при вивченні курсу "Теорія ймовірностей та математична статистика». Автори пропонують ознайомити здобувачів із узагальнюючими алгоритмами отримання базових статистичних функиій $\chi^{2}$, Ст'юдента та ФімераСнедекора розподілів випадкових величин, які вибирає дослідник відповідно до виду альтернативної гіпотези.

Ключові слова: математична статистика, узагальнення, алгоритм, розподіли $\chi 2$, Ст'юдента та Фішера-Снедекора.
Аннотация. B cтатье рассмотрены вопросы обобщения знаний соискателей при изучения курса "Теория вероятностей $u$ математическая статистика». Aвторы предлагают ознакомить соискателей из обобщаюшими алгоритмами получения базовых статистических функиий $\chi^{2}$, Стьюдента и Фишера-Снедекора распределений случайных величин, которые выбирает исследователь в соответствии с видом альтернативной гипотезы.

Ключевые слова: математическая статистика, обобщение, алгоритм, распределения ұ2, Стьюдента и Фишера-Снедекора 
Постановка проблеми. Широке впровадження математико-статистичних методів в економічний аналіз, автоматизація процесів збору, зберігання і систематизації, передачі й обробки інформації зумовлюють нові підходи щодо визначення предмета, змісту і структури статистичної теорії. Економічна реформа ставить вимоги i до якості викладання статистики. Оскільки рівень навчальної літератури та рівень викладання зумовлюються ступенем наукової розробки проблем навчальної дисципліни, підручники повинні містити останні досягнення в даній науці i бути адекватними прогресивним формам навчання. Слід зацікавити аудиторію його сутністю й проблемністю вирішення [1].

Відсутність у випускників-економістів глибоких знань із питань прийомів i способів пізнання та комплексного використання методів дослідження, які викладаються в навчальних курсах статистики (особливо питання математичної статистики), слід вважати суттєвим недоліком освітнього процесу, оскільки в системі економічної освіти важливу роль відіграють статистичні дисципліни. Лише їх знання можуть сприяти поглибленому розкриттю та поясненню складних економічних процесів і явищ.

Озброєння майбутніх фахівців у галузі економіки цими методами дозволяє розкрити іiі глибинні процеси та перейти до більш досконалих моделей управління нею.

Зрозуміло, що трансформація економіки орієнтує на нові завдання, які потребують перебудови економічного мислення у напрямку поглиб- лення знань статистичної методології. Тому освітній процес повинен забезпечити можливість одержання здобувачами знань методології та методики поглибленого економічного аналізу з комплексним використанням традиційних статистичних і сучасних математико-статистичних методів.

Вищій школі потрібні високоякісні знання з статистичних дисциплін, які б озброювали здобувачів глибокими знаннями сучасної статистики як необхідного елемента й однієї 3 найважливіших функцій управління. Це зумовлено специфікою навчального матеріалу, який містить велику кількість понять, фактів, задач різних типі тощо. Вміння узагальнювати i систематизувати не тільки сприяють кращому засвоєнню навчального матеріалу, але й виховують у майбутніх фахівців розуміння необхідності встановлення зв'язків між поняттям, пошуку загальних підходів, вміння використовувати загальні правила у конкретних випадках [1-4].

Слід звернути увагу на складність в засвоєнні статистичних дисциплін, що мають багато причин. Від об'єктивних - не завжди абітурієнти володіють достатнім рівнем математичної підготовки. До суб'єктивних - не встановлений необхідний контакт викладач - здобувач. Але методика, що застосовується викладачем, повинна враховувати чинники, що можуть впливати на якість засвоєння матеріалу [3].

Викладач повинен орієнтуватися на набутті здобувачами наступних знань i вмінь, що $\epsilon$ головними завданням 
дисциплін 3 математичної статистики [4]:

- вирізняти задачі певних типів;

- засвоєнні основних статистичних термінів та методів;

- застосовувати статистичний апарат 3 використанням прикладних програм аналізу даних;

- розуміти загальні алгоритми та методи розв'язування статистичних задач різних типів;

- використовувати

загальні

алгоритми для розв'язування конкретних статистичних задач, зокрема прикладного змісту.

- набуття уміння побудувати модель, що адекватно відображає дійсність i застосувати результати статистичного аналізу в управлінні економічними і фінансовими процесами і об'єктами.

Тому перед викладачем вищої школи стає питання щодо організації освітньої діяльності здобувача, яка сприяє більш ефективному засвоєнню знань, розвитку мислення та формуванню загальних прийомів навчальної роботи. Вибір методичних прийомів, форм та засобів навчання залежать, зокрема, від специфіки навчального курсу. На нашу думку, подальшої розробки потребують методичні аспекти формування у здобувачів умінь узагальнювати та систематизувати знання на різних етапах засвоєння навчального матеріалу 3 використанням узагалінюючих алгоритмів отримання базових статистичних функцій.

Між тим, використовуючи відомий здобувачам базовий математичний апарат, нескладно показати алгоритми отримання виразів цих статистичних функцій у ряді простих випадків для невеликих ступенів вільності та порівняти результати цих обчислень із результатами, отриманими від загальних виразів.

Узагальнення та систематизація знань $\epsilon$ ефективним засобом поглиблення, універсалізації, впорядкування, розуміння та запам'ятовування знань. Багато розрізнених фактів, явищ, прикладів при знаходженні загальних принципів стають ілюстрацією загальних положень. Це сприяє кращому запам'ятовуванню та більш ефективному застосуванню знань. Крім того, виводить здобувачів на принципово новий рівень розуміння. Узагальнення знань дозволяе розвивати вміння розв'язувати задачі шляхом перенесення способу дій на цілий клас аналогічних задач, що $\epsilon$ одним 3 основних завдань навчання. Необхідність систематизації та узагальнення знань зумовлена багатьма причинами. При узагальненні навчального матеріалу не тільки відтворюються найбільш значимі факти, поняття, уміння, але й встановлюються логічні зв'язки між ними. Навчальний матеріал при цьому переосмислюється повністю, що приводить не тільки до зміцнення засвоєного, але й до побудови знань в структурну систему, що підвищує якість засвоєння навчального матеріалу, розвиває розумову діяльність.

Власний досвід викладання курсу «Теорія ймовірностей та елементи математичної статистики» доводить ефективність цілеспрямованої реалізації міжпонятійних та тематичних узагальнень та систематизації знань 
студентів за допомогою узагалінюючих алгоритмів отримання базових статистичних функцій при засвоєнні навчального матеріалу 3 математичної статистики.

Необхідно заповнити прогалину у навчальних матеріалах між базовими початковими

означеннями

та

складними формулами статистичних функцій, пов'язаних с гаммафункцією Ейлера, що сприятиме кращому розумінню здобувачами математичного апарату статистики.

Аналіз останніх досліджень i публікацій. Розподіли $\chi^{2}$, Ст'юдента та Фішера-Снедекора відіграють надзвичайно велику роль у математичній статистиці. Обгрунтування цих розподілів було у свій час важливою теоретичною роботою, яка була виконана відомими вченими Ф.Р. Хельмертом (1876) [11], К. Пірсоном (1900) [12], В. Госсетом (1908) [13], Р.А. Фішером (1924) [14]. Достатньо детально математичний апарат статистики описаний у ряді фундаментальних праць, зокрема у книзі Г. Крамера (1946) «Математичні методи статистики».

Зрозуміло, що, оскільки у теоретичному аспекті усі проблеми, пов'язані із цими розподілами вирішені, обгрунтовані та багатократно перевірені, то у практичному використанні статистичних функцій немає потреби згадувати теоретичні деталі та логіку виведення відповідних математичних формул.

Інша справа - ефективне засвоєння здобувачами знань 3 математичної статистики. Викладачу недостатньо стверджувати, що величина $\sum_{i=1}^{k} Z_{i}^{2}$ має розподіл $\chi^{2}$, а величина $t=Z / \sqrt{\frac{1}{k} \chi^{2}}-$ розподіл Ст'юдента і т.д. Як правило, учбова література обмежується лише означеннями статистичних функцій, або формулами $\chi^{2}, \boldsymbol{t}$ та $\boldsymbol{F}$, що виражені через гамма-функцію Ейлера [5; 15-18]. Якщо врахувати, що теорія гамма-функції (Г-функціi) Ейлера у програмі математичної підготовки здобувачів освіти не математичних спеціальностей, як правило, відсутня, то поява цих формул у такому форматі дидактично не обгрунтована i часто незрозуміла.

Між тим, за допомогою доступних алгоритмів не складно показати механізм отримання цих формул, якщо не у загальному випадку, що $\epsilon$ достатньо складною задачею, то хоч би для декількох частинних випадків. Саме цього бракує у більшості підручниках. Пропонуємо, використовуючи відомий студентам базовий математичний апарат, алгоритм обчислення цих статистичних функцій у ряді простих випадків для невеликих ступенів вільності.

Мета статті полягає в розробці простих і зручних алгоритмів, в яких узагальнено способи отримання базових статистичних функцій розподілу випадкових величин у процесі засвоєння студентами навчального матеріалу 3 математичної статистики. Дидактичною метою нашої роботи є розширення списку вправ та задач для розділу математичної статистики «Функції випадкового аргументу», які можна застосувати у освітньому процесі. 
У роботі використаний програмний матеріал 3 математичної статистики: задачу знаходження щільності та функції розподілу функції випадкової величини, задачу знаходження щільності та функції розподілу функції суми або частки двох випадкових величин. 3 курсу математики використані відомі здобувачам правила диференціювання та інтегрування неперервних функцій.
Виклад основного матеріалу. Розглянемо задачі знаходження розподілів $\chi^{2}$, Ст'юдента та $\mathrm{F}$ для довільних ступенів вільностей.

Основна ідея обчислень полягає у послідовному знаходженні результатів від малих до більших ступенів вільності за допомогою рекурентних залежностей.

\section{Розподіл $\chi^{2}$.}

Розподілом $\chi^{2} \quad$ (хі-квадрат) $3 \mathrm{k}$ ступенями вільності називається розподіл суми квадратів незалежних випадкових величин, що розподілені за стандартним нормальним законом, тобто $\chi^{2}=\sum_{i=1}^{k} Z_{i}^{2}$, де $Z_{\mathrm{i}}(i=1,2, \ldots, k)$ має нормальний розподіл $3 \quad M\left(Z_{\mathrm{i}}\right)=0$ та $\sigma_{\mathrm{i}}=1$.

Виконуємо перше обчислення. Випадкова величина $\mathrm{X}$ розподілена нормально, $M(X)=0, \sigma^{2}=1$. У цьому випадку щільність розподілу випадкової величини описується локальною функцією Лапласа $\varphi(x)=\frac{1}{\sqrt{2 \pi}} e^{-\frac{x^{2}}{2}} \cdot \quad$ Поставимо задачу знаходження розподілу немонотонної функції $Y=X^{2}$, який можна вважати розподілом $\chi^{2}$ для ступеню вільності $k=1$.

Ця задача достатньо проста, часто зустрічається у підручниках, а тому наведемо результат обчислень.
Щільність розподілу $\chi^{2}$ для $\mathrm{k}=1$ :

$$
g\left(\chi^{2}\right)=\frac{1}{\sqrt{2 \pi x}} e^{-x / 2} ; x \geq 0 .
$$

2. Поставимо задачу знаходження розподілу функції $\chi^{2}=z_{1}^{2}+z_{2}^{2}$, що $\epsilon$ розподілом $\chi^{2}$ для ступеню вільності $k=2$. Використаємо попередній результат обчислень та скористаємося позначеннями:

$z_{1}^{2}=p ; z_{2}^{2}=q ; \chi^{2}=y ; y=p+q$.

При цьому, шуканий розподіл $g(y)$ знаходимо як згортку розподілів $\quad g_{1}(p)=\frac{1}{\sqrt{2 \pi p}} e^{-p / 2} \quad$ та $g_{2}(q)=\frac{1}{\sqrt{2 \pi q}} e^{-q / 2}$.

Теорія пропонує наступну процедуру:

$$
g(y)=\int_{0}^{\infty} g_{1}(p) \cdot g_{2}(y-p) d p .
$$

Далі проводимо обчислення, які дають наступний результат: 


$$
\begin{aligned}
& g(y)=\int_{0}^{y} \frac{1}{p^{1 / 2} \cdot \sqrt{2 \pi}} \cdot e^{-\frac{p}{2}} \cdot \frac{1}{(z-p)^{1 / 2} \cdot \sqrt{2 \pi}} \cdot e^{-\frac{y-p}{2}} d p= \\
& =\frac{1}{2 \pi} \int_{0}^{y} \frac{e^{-\frac{p}{2}-\frac{y-p}{2}}}{p^{1 / 2} \cdot(y-p)^{1 / 2}} d p=\frac{e^{-\frac{y}{2}}}{2 \pi} \int_{0}^{y} \frac{1}{p^{1 / 2} \cdot(y-p)^{1 / 2}} d p= \\
& =\left.\frac{e^{-\frac{y}{2}}}{2 \pi}\left[2 \operatorname{arctg} \sqrt{\frac{p}{y-p}}\right]\right|_{0} ^{y}=\frac{e^{-\frac{y}{2}}}{2 \pi} 2 \operatorname{arctg}(\infty)=\frac{e^{-\frac{y}{2}}}{2 \pi} 2 \frac{\pi}{2}=\frac{e^{-\frac{y}{2}}}{2} .
\end{aligned}
$$
Отримана таким чином щільність Знайдемо розподіл функції $\chi_{k=3}^{2}=\sum_{i=1}^{3} z_{i}^{2}$,
розподілу $\chi^{2}$ для $k=2$ :

$$
g\left(\chi^{2}\right)=\frac{e^{-\frac{\chi^{2}}{2}}}{2}
$$

який являє собою розподіл $\chi^{2}$ для ступеню вільності $k=3$. Використаємо

3. Продовжуємо обчислення, вже обчислені попередньо розподіли та введемо

позначення: використовуючи формулу згортки. $z_{1}^{2}+z_{2}^{2}=p ; z_{2}^{2}=q ; \chi^{2}=y ; y=p+q$.

Шуканий розподіл $g(y)$ знаходимо як згортку розподілів $g_{1}(p)=\frac{1}{2} e^{-p / 2}$ та

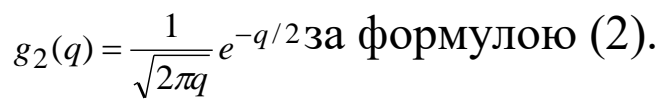

Використовуючи результат обчислення інтегралу,

$$
\int \frac{1}{(y-p)^{1 / 2}} d p=\left|\begin{array}{c}
x=y-p \\
d x=-d p
\end{array}\right|=-\int \frac{d x}{x^{1 / 2}}=-2 x^{1 / 2}=2(y-p)^{1 / 2}+c,
$$

отримаємо значення щільності розподілу $g(y)$ :

$$
\begin{aligned}
& g(y)=\int_{0}^{y} \frac{1}{2} \cdot e^{-\frac{p}{2}} \cdot \frac{1}{(y-p)^{1 / 2} \cdot \sqrt{2 \pi}} \cdot e^{-\frac{y-p}{2}} d p=\frac{1}{2 \sqrt{2 \pi}} \int_{0}^{y} \frac{e^{-\frac{p}{2}-\frac{y-p}{2}}}{(y-p)^{1 / 2}} d p= \\
& =\frac{e^{-\frac{y}{2}}}{2 \pi} \int_{0}^{y} \frac{1}{(y-p)^{1 / 2}} d p=\left.\frac{e^{-\frac{y}{2}}}{2 \sqrt{2 \pi}}\left[-2(y-p)^{1 / 2}\right]\right|_{0} ^{y}=\frac{e^{-\frac{y}{2}}}{2 \sqrt{2 \pi}} 2 \sqrt{y}==\frac{e^{-\frac{y}{2}}}{\sqrt{2} \pi} \sqrt{y} .
\end{aligned}
$$

Щільність розподілу $\chi^{2}$ для $k=3$ :

$$
g\left(\chi^{2}\right)=\frac{e^{-\frac{\chi^{2}}{2}}}{\sqrt{2} \pi} \sqrt{\chi^{2}} .
$$

знайдемо розподіл $\chi_{k=4}^{2}=\sum_{i=1}^{4} z_{i}^{2}$.

\section{Введемо}

позначення:
4. Очевидно, у такий спосіб, комбінуючи у формулі згортки вже знайдені розподіли, неважко знати розподіли для більших значень ступеню вільності k. Наприклад, $\chi^{2}=\sum_{i=1}^{4} z_{i}^{2} ; z_{1}^{2}+z_{2}^{2}=p ; z_{, 3}^{2}+z_{4}^{2}=q ; \chi^{2}=y \quad$ та отримаємо згортку $g(y)$ 


$$
\begin{gathered}
y=p+q ; \quad g(y)=\int_{0}^{\infty} f_{1}(p) \cdot f_{2}(q) d p=\int_{0}^{\infty} f_{1}(p) \cdot f_{2}(s-p) d p \\
g(y)=\int_{0}^{y} \frac{1}{2} \cdot e^{-\frac{p}{2}} \cdot \frac{1}{2} \cdot e^{-\frac{y-p}{2}} d p==\frac{1}{4} \int_{0}^{y} e^{-\frac{p}{2}-\frac{y-p}{2}} d p=\frac{e^{-\frac{y}{2}}}{4} \int_{0}^{y} d p=\frac{e^{-\frac{y}{2}}}{4}[p]_{0}^{y}=\frac{e^{-\frac{y}{2}}}{4} y
\end{gathered}
$$

Щільність розподілу $\chi^{2}$ для $k=4$ :

$$
g\left(\chi^{2}\right)=\frac{e^{-\frac{\chi^{2}}{2}}}{4} \chi^{2} .
$$

Зрозуміло, що така ідея обчислень дозволяє на підставі вже зроблених розрахунків (1); (3)-(5) відносно просто отримати результати для більших значень ступенів вільності.

Отже, для $k=n$ потрібно обчислити згортку 3 відповідними попередньо обчисленими розподілами iз ступенями вільності $k<n$.

5. Виконаємо перевірку отриманих значень розподілу $\chi^{2}$ із результатами підстановки у загальний вираз цього розподілу через гамма-функцію:

$$
f(x)=\left\{\begin{array}{lr}
\frac{1}{2^{\frac{k}{2}} \cdot \Gamma\left(\frac{k}{2}\right)} x^{\frac{k}{2}-1} \cdot e^{-\frac{x}{2}} n p u \quad & x \geq 0 \\
0 & \text { nрu } \quad x<0,
\end{array}\right.
$$

де $\quad \Gamma(y)=\int_{0}^{+\infty} e^{-t} t^{y-1} d t \quad-\quad \Gamma$-функція Ейлера.

Бачимо, що для цілих додатних значень $y=n$ маємо: $\Gamma(n)=(n-1) !$, а для напівцілих $\Gamma(1 / 2+n)=\frac{(2 n) !}{4^{n} n !} \sqrt{\pi}$.

\section{Розподіл Ст'юдента}

Розподілом Стьюдента (або $t$ - нормованим нормальним законом, розподілом) називається розподіл випадкової величини: $t=\frac{Z}{\sqrt{\frac{1}{k} \chi^{2}}}$, де $Z$ випадкова величина, розподілена за
Отже: для $y=1$ отримаємо $\Gamma(1)=1$, $y=2: \Gamma(2)=1$,

для $y=1 / 2$ отримаємо $\Gamma(1 / 2)=\sqrt{\pi}, \mathrm{a}$ для $y=3 / 2: \Gamma(3 / 2)=\frac{1}{2} \sqrt{\pi}$.

Зробимо підстановку

$$
f_{k=1}(x)=\frac{1}{2^{\frac{1}{2}} \cdot \Gamma\left(\frac{1}{2}\right)} x^{\frac{1}{2}-1} \cdot e^{-\frac{x}{2}}=\frac{e^{-\frac{x}{2}}}{\sqrt{2 \pi x}}
$$

$$
f_{k=2}(x)=\frac{1}{2^{\frac{2}{2}} \cdot \Gamma\left(\frac{2}{2}\right)} x^{\frac{2}{2}-1} \cdot e^{-\frac{x}{2}}=\frac{e^{-\frac{x}{2}}}{2}
$$

$$
\begin{aligned}
& f_{k=3}(x)=\frac{1}{2^{\frac{3}{2}} \cdot \Gamma\left(\frac{3}{2}\right)} x^{\frac{3}{2}-1} \cdot e^{-\frac{x}{2}}=\frac{e^{-\frac{x}{2}}}{\sqrt{2 \pi}} \sqrt{x} \\
& f_{k=4}(x)=\frac{1}{2^{\frac{4}{2}} \cdot \Gamma\left(\frac{4}{2}\right)} x^{\frac{4}{2}-1} \cdot e^{-\frac{x}{2}}=\frac{e^{-\frac{x}{2}}}{4} x
\end{aligned}
$$

що збігається з формулами (1), (3)-(5).

Отже, маємо повну відповідність результатів підстановки у загальну формулу $\chi^{2} \quad 3$ результатами вище проведених обчислень. 
Для знаходження розподілу Ст'юдента використаємо дещо складнішу процедуру обчислень порівняно із попередньою задачею. Для того, щоб скористатися способом знаходження розподілу результату ділення однієї випадкової величини на

іншу

$$
F\left(\frac{Z}{y}\right)=\iint_{z, y} g_{1}(Z) g_{3}(y) d z d y,
$$

потрібно спочатку знайти щільність розподілу величини $y=f\left(\chi^{2}\right)=\sqrt{\frac{1}{k} \chi^{2}}$ (щільність розподілу величини $y$ - знаменника $t$ ). Оскільки ми не використовуємо загальну формулу розподілу Ст'юдента, то змушені знаходити розподіл

$$
\begin{aligned}
& y=f\left(\chi^{2}\right)=\sqrt{\chi^{2}}, \text { звідки } \quad \chi^{2}=f^{-1}(y)=y^{2} ;\left(f^{-1}(y)\right)=2 y ; \\
& g_{3}(y)=\frac{1}{\sqrt{2 \pi y^{2}}} e^{-\frac{y^{2}}{2}} \cdot 2 y=\frac{2}{\sqrt{2 \pi}} e^{-\frac{y^{2}}{2}} .
\end{aligned}
$$

Отже, $g_{3}(y)=\frac{2}{\sqrt{2 \pi}} e^{-\frac{y^{2}}{2}}$ або $g_{3}\left(\sqrt{\chi^{2}}\right)=\frac{2}{\sqrt{2 \pi}} e^{-\frac{\chi^{2}}{2}}$.

Далі знаходимо розподіл частки подібно знаходженню розподілу суми:

$$
F\left(\frac{Z}{y}\right)=\iint_{z, y} g(Z) g(y) d z d y=\iint_{z, y} \frac{1}{\sqrt{2 \pi}} e^{-\frac{z^{2}}{2}} \cdot \frac{2}{\sqrt{2 \pi}} e^{-\frac{y^{2}}{2}} d z d y ; \frac{Z}{y}=x,
$$

звідки $Z=x y ; d z=y d x$;

$$
\begin{aligned}
& F\left(\frac{Z}{y}\right)=\int_{-\infty}^{t} d x \int_{0}^{\infty} \frac{1}{\sqrt{2 \pi}} e^{-\frac{x^{2} y^{2}}{2}} \frac{2}{\sqrt{2 \pi}} e^{-\frac{y^{2}}{2}} y d y=\frac{1}{\pi} \int_{-\infty}^{t} d x \int_{0}^{\infty} e^{-\frac{\left(x^{2}+1\right) y^{2}}{2}} y d y= \\
& =\left|\frac{\left(x^{2}+1\right) y^{2}}{2}=p ;\right|=\int_{-\infty}^{t} d x\left[\frac{1}{\pi\left(x^{2}+1\right)} \int_{0}^{\infty} e^{-p} d p\right]=\int_{-\infty}^{t} d x\left[\frac{1}{\pi\left(x^{2}+1\right)}\right] .
\end{aligned}
$$

Таким чином, функція розподілу Ст'юдента для $k=1$ інтеграл $F(x)$, а щільність розподілу

підінтегральний вираз:

$$
g(t)=\frac{1}{\pi\left(t^{2}+1\right)} ;
$$

$$
F(t)=\frac{1}{\pi} \int_{-\infty}^{t} \frac{1}{\left(x^{2}+1\right)} d x=\left.\frac{1}{\pi} \cdot \operatorname{arctg} x\right|_{-\infty} ^{t}=\frac{1}{\pi}\left(\operatorname{arctg} t+\frac{\pi}{2}\right) .
$$


У подальших обчисленнях не будемо обчислювати $F(x)$, а лише щільність $g(x) . \quad \mathrm{V}$ статистичних задачах для обчислень

2. Задача знаходження розподілу Ст'юдента для $k=2$ розв'язується аналогічно попередній.

Спочатку знаходимо щільність використовують саме щільність розподілу $g_{3}\left(\sqrt{\frac{1}{2} \chi^{2}}\right)$ :
розподілу, а не функцію розподілу.

$$
\begin{gathered}
g_{1}(Z)=\frac{1}{\sqrt{2 \pi}} e^{-\frac{z^{2}}{2}} ; \quad g_{2}\left(\chi^{2}\right)=\frac{1}{2} e^{-\frac{\chi^{2}}{2}} ; \quad t=\frac{Z}{\sqrt{\frac{1}{2} \chi^{2}}} ; \\
y=f\left(\chi^{2}\right)=\sqrt{\frac{1}{2} \chi^{2}}, \text { звідки } \chi^{2}=f^{-1}(y)=2 y^{2} ;\left(f^{-1}(y)\right)=4 y ; \\
g_{3}(y)=\frac{1}{2} e^{-y^{2}} \cdot 4 y=2 y \cdot e^{-y^{2}} \text { або } g_{3}\left(\sqrt{\frac{1}{2} \chi^{2}}\right)=\sqrt{2 \chi^{2}} \cdot e^{-\frac{1}{2} \chi^{2}} .
\end{gathered}
$$

Далі шукаємо щільність та функцію розподілу $t=Z / \sqrt{\frac{1}{2} \chi^{2}}=Z / y$, використавши позначення: $\frac{Z}{y}=x$, звідки $Z=x y ; d z=y d x$;

$$
\begin{aligned}
& F\left(\frac{Z}{y}\right)=\iint_{z, y} g(Z) g(y) d z d y=\iint_{z, y} \frac{1}{\sqrt{2 \pi}} e^{-\frac{z^{2}}{2}} \cdot 2 y \cdot e^{-y^{2}} d z d y=\int_{-\infty}^{t} d x \int_{0}^{\infty} \frac{1}{\sqrt{2 \pi}} e^{-\frac{x^{2} y^{2}}{2}} 2 y e^{-y^{2}} y d y= \\
& =\frac{1}{\sqrt{2 \pi}} \int_{-\infty}^{t} d x \int_{0}^{\infty} e^{-\left(\frac{x^{2}}{2}+1\right) y^{2}} 2 y^{2} d y==\left|\begin{array}{l}
\left(\frac{x^{2}}{2}+1\right) y^{2}=p^{2} ; \\
\left(\frac{x^{2}}{2}+1\right)^{\frac{1}{2}} y=p ; \\
d p=\left(\frac{x^{2}}{2}+1\right)^{\frac{1}{2}} y d y
\end{array}\right|=\int_{-\infty}^{t} d x\left[\frac{1}{\sqrt{2 \pi}\left(\frac{x^{2}}{2}+1\right)^{\frac{3}{2}} \int^{\infty} e^{-p^{2}} 2 p^{2} d p}\right] \Rightarrow \\
& \Rightarrow \int_{-\infty}^{t} d x\left[\frac{1}{\sqrt{2 \pi}\left(\frac{x^{2}}{2}+1\right)^{\frac{3}{2}}} \cdot \frac{\sqrt{\pi}}{2}\right]=\int_{-\infty}^{t} d x\left[\frac{1}{2 \sqrt{2}\left(\frac{x^{2}}{2}+1\right)^{\frac{3}{2}}}\right] .
\end{aligned}
$$

Вираз результату обчислень у 3. Щільність розподілу Ст'юдента квадратних дужках $\epsilon$ щільність для $k=3$. Задача знаходження розподілу Ст'юдента для $k=2$ :

$$
g(t)=\frac{1}{2 \sqrt{2}\left(\frac{t^{2}}{2}+1\right)^{\frac{3}{2}}} .
$$

(7) попереднім:

$$
g(Z)=\frac{1}{\sqrt{2 \pi}} e^{-\frac{z^{2}}{2}} ; g\left(\chi^{2}\right)=\frac{\sqrt{\chi^{2}}}{\sqrt{2} \pi} e^{-\frac{\chi^{2}}{2}} .
$$


Спочатку знаходимо щільність розподілу $g_{3}\left(\sqrt{\frac{1}{3} \chi^{2}}\right)$,

$$
\begin{aligned}
& y=f\left(\chi^{2}\right)=\sqrt{\frac{1}{3} \chi^{2}}, \text { звідки } \chi^{2}=f^{-1}(y)=3 y^{2} ;\left(f^{-1}(y)\right)=6 y ; \\
& g(y)=\frac{\sqrt{3 y^{2}}}{\sqrt{2} \pi} e^{-\frac{3 y^{2}}{2}} \cdot 6 y=\frac{1}{\sqrt{2 \pi}} 6 \sqrt{3} y^{2} \cdot e^{-\frac{3 y^{2}}{2}} .
\end{aligned}
$$

Далі шукаємо щільність та функцію розподілу $t=Z / \sqrt{\frac{1}{2} \chi^{2}}=Z / y ;$, при $\frac{Z}{y}=x$, звідки $Z=x y ; d z=y d x:$

$$
\begin{aligned}
& F\left(\frac{Z}{y}\right)=\iint_{z, y} g(Z) g(y) d z d y=\iint_{z, y} \frac{1}{\sqrt{2 \pi}} e^{-\frac{z^{2}}{2}} \cdot \frac{1}{\sqrt{2 \pi}} 6 \sqrt{3} y^{2} \cdot e^{-\frac{3 y^{2}}{2}} d z d y= \\
& =\int_{-\infty}^{t} d x \int_{0}^{\infty} \frac{1}{\sqrt{2 \pi}} e^{-\frac{x^{2} y^{2}}{2}} \frac{1}{\sqrt{2 \pi}} 6 \sqrt{3} y^{2} \cdot e^{-\frac{3 y^{2}}{2}} y d y=\frac{2 \sqrt{3}}{2 \pi} \int_{-\infty}^{t} d x \int_{0}^{\infty} e^{-\left(\frac{x^{2}}{3}+1\right) \frac{3 y^{2}}{2}} y^{2} 3 y d y=
\end{aligned}
$$

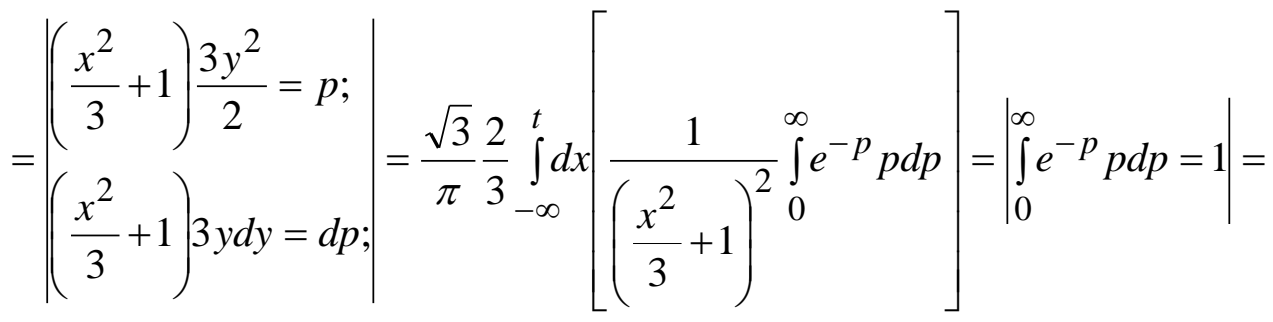

$$
\begin{aligned}
& =\int_{-\infty}^{t} d x\left[\frac{2}{\pi \sqrt{3}} \frac{1}{\left(\frac{x^{2}}{3}+1\right)^{2}}\right]
\end{aligned}
$$

Вираз у квадратних дужках результату обчислень $є$ щільність розподілу Ст'юдента для $k=3$ :

$$
g(t)=\frac{2}{\pi \sqrt{3}} \frac{1}{\left(\frac{t^{2}}{3}+1\right)^{2}} .
$$

Продовжуючи

обчислення подібним чином можемо знаходити розподіл Ст'юдента для інших ступенів вільності, попередньо знайшовши розподіл відповідної $\chi^{2}$
4. Порівняємо отримані результати із загальною формулою для розподілу Ст'юдента:

$$
f(t)=\frac{\Gamma\left(\frac{k+1}{2}\right)}{\Gamma\left(\frac{k}{2}\right) \sqrt{\pi k}}\left(1+\frac{t^{2}}{k}\right)^{-\frac{k+1}{2}} .
$$

Зробимо підстановку наведених вище відповідних значень Г-функції: 


$$
\begin{gathered}
f_{k=1}(t)=\frac{\Gamma\left(\frac{1+1}{2}\right)}{\Gamma\left(\frac{1}{2}\right) \sqrt{\pi \cdot 1}}\left(1+\frac{t^{2}}{1}\right)^{-\frac{1+1}{2}}=\frac{1}{\pi}\left(1+t^{2}\right)^{-1} \\
f_{k=2}(t)=\frac{\Gamma\left(\frac{2+1}{2}\right)}{\Gamma\left(\frac{2}{2}\right) \sqrt{\pi \cdot 2}}\left(1+\frac{t^{2}}{2}\right)^{-\frac{2+1}{2}}= \\
=\frac{\sqrt{\pi}}{2 \sqrt{\pi \cdot 2}}\left(1+\frac{t^{2}}{2}\right)^{-\frac{3}{2}}=\frac{1}{2 \sqrt{2}}\left(1+\frac{t^{2}}{2}\right)^{-\frac{3}{2}}
\end{gathered}
$$

$$
\begin{aligned}
& f_{k=3}(t)=\frac{\Gamma\left(\frac{3+1}{2}\right)}{\Gamma\left(\frac{3}{2}\right) \sqrt{\pi \cdot 3}}\left(1+\frac{t^{2}}{3}\right)^{-\frac{3+1}{2}}= \\
& =\frac{1}{\frac{1}{2} \sqrt{\pi} \sqrt{\pi \cdot 3}}\left(1+\frac{t^{2}}{3}\right)^{-\frac{4}{2}}=\frac{2}{\pi \sqrt{3}}\left(1+\frac{t^{2}}{3}\right)^{-2}
\end{aligned}
$$

Маємо повну відповідність результатів підстановки у загальну формулу 3 результатами вище проведених обчислень (6)-(8).

\section{Розподіл Фішера-Снедекора}

Розподілом Фішера-Снедекора (або F-розподілом) називається розподіл випадкової величини $F=\frac{\frac{1}{k_{1}} \chi^{2}\left(k_{1}\right)}{\frac{1}{k_{2}} \chi^{2}\left(k_{2}\right)}$, де $\chi^{2}\left(k_{1}\right)$ і $\chi^{2}\left(k_{2}\right)$ - випадкові величини, що мають $\chi 2$-розподіл відповідно $3 k_{1} \mathrm{i}$ $k_{2}$ степенями вільності.

1. Поставимо задачу знайти розподіл функції Фішера-Снедекора $F$ для частинного випадку де

$$
\chi^{2}\left(k_{1}=3\right)=\mathrm{p}-g_{1}(p)=\frac{e^{-\frac{p}{2}}}{\sqrt{2 \pi}} \sqrt{p} ; \chi^{2}\left(k_{2}=4\right)=q-g_{2}(q)=\frac{e^{-\frac{q}{2}}}{4} q .
$$

Шукаємо функцію розподілу

$$
\begin{gathered}
G\left(\frac{k_{2} p}{k_{1} q}\right)=\iint_{p, q} g_{1}(p) g_{2}(q) d p d q=\iint_{p, q} \frac{e^{-\frac{p}{2}}}{\sqrt{2 \pi}} \sqrt{p} \cdot \frac{e^{-\frac{q}{2}}}{4} q \cdot d p d q \\
\frac{k_{2} p}{k_{1} q}=x, \text { звідкu } p=\frac{k_{1}}{k_{2}} x q ; d p=\frac{k_{1}}{k_{2}} q d x ; \\
G\left(\frac{4}{3} \frac{p}{q}\right)=\iint_{p, q} g_{1}(p) g_{2}(q) d p d q=\iint_{x, q} \frac{e^{-\frac{3}{4} \frac{x}{2}}}{\sqrt{2 \pi}} \sqrt{\frac{3}{4} x q} \cdot \frac{e^{-\frac{q}{2}}}{4} q \cdot \frac{3}{4} q d x d q ; \\
G\left(\frac{4}{3} \frac{p}{q}\right)=\int_{0}^{F} d x \int_{0}^{\infty} \frac{1}{4 \sqrt{2 \pi}} e^{-\frac{3}{4} \frac{x q}{2}} \sqrt{\frac{3}{4} x} \frac{k_{1}}{k_{2}} e^{-\frac{q}{2}} q^{\frac{5}{2}} d q=\frac{1}{4 \sqrt{2 \pi}}\left(\frac{3}{4}\right)^{\frac{3}{2} F} \int_{0}^{\sqrt{x}} d x \int_{0}^{\infty} e^{-\frac{\left(-\frac{3}{4} x+1\right) q}{2}} q^{\frac{5}{2}} d q=
\end{gathered}
$$

\section{Скористасмося формулами} попередніх обчислень (4) та (5): 


$$
\begin{aligned}
& \left|\begin{array}{l}
\frac{\left(\frac{3}{4} x+1\right) q}{2}=y ; \\
d y=\frac{\left(\frac{3}{4} x+1\right)}{2} d q \\
q=\frac{2 y}{\left(\frac{3}{4} x+1\right)}
\end{array}\right|=\frac{1}{4 \sqrt{2 \pi}}\left(\frac{3}{4}\right)^{\frac{3}{2}} \int_{0}^{F} \frac{2^{\frac{7}{2}} \sqrt{x} d x}{\left(\frac{3}{4} x+1\right)^{\frac{7}{2}}} \int^{\infty} e^{-y} y^{\frac{5}{2}} d y=\left|\int_{0}^{\infty} e^{-y} y^{\frac{5}{2}} d y=\frac{15}{8} \sqrt{\pi}\right|= \\
& \int_{0}^{F} \frac{1}{4 \sqrt{2 \pi}}\left(\frac{3}{4}\right)^{\frac{3}{2}} \frac{2^{\frac{7}{2}} \sqrt{x}}{\left(\frac{3}{4} x+1\right)^{\frac{7}{2}}} \frac{15}{8} \sqrt{\pi} d x=\int_{0}^{F} \frac{180 \sqrt{3 x}}{(3 x+4)^{\frac{7}{2}}} d x
\end{aligned}
$$

Отже, маємо щільність $F$ - частинного випадку, де $\chi^{2}\left(k_{1}=4\right)$, а розподілу, для $k_{1}=3$, а $k_{2}=4$ :

$$
g(x)=\frac{180 \sqrt{3 x}}{(3 x+4)^{\frac{7}{2}}} .
$$

знаменник також - $\chi^{2}\left(k_{2}=4\right)$. Попередні обчислення щільності розподілів відповідних величин та позначення у цьому випадку:

2. Знайдемо розподіл функції Фішера-Снедекора $\quad-\quad F$ для

$$
\chi^{2}\left(k_{1}=4\right)=\mathrm{p}-g_{1}(p)=\frac{e^{-\frac{p}{2}}}{4} p ; \quad \chi^{2}\left(k_{2}=4\right)=q-g_{2}(q)=\frac{e^{-\frac{q}{2}}}{4} q .
$$

Шукаємо функцію розподілу, врахувавши, що: $\frac{k_{2} p}{k_{1} q}=x, p=\frac{4}{4} x q=x q ; d p=q d x$;

$$
\begin{aligned}
& G\left(\frac{k_{2} p}{k_{1} q}\right)=\iint_{p, q} g_{1}(p) g_{2}(q) d p d q=\iint_{p, q} \frac{e^{-\frac{p}{2}}}{4} p \cdot \frac{e^{-\frac{q}{2}}}{4} q \cdot d p d q= \\
& =\iint_{x, q} \frac{e^{-\frac{x q}{2}}}{4} x q \cdot \frac{e^{-\frac{q}{2}}}{4} q \cdot q d x d q=\int_{0}^{F} \frac{x d x}{16} \int_{0}^{\infty} e^{-\frac{(x+1) q}{2}} q^{3} d q= \\
& =\left|\begin{array}{l}
\frac{(x+1) q}{2}=y ; \\
d y=\frac{(x+1)}{2} d q \\
q=\frac{2 y}{(x+1)}
\end{array}\right|=\int_{0}^{F} \frac{2^{4} x d x}{16(x+1)^{4}} \int_{0}^{\infty} e^{-y} y^{3} d y=\left|\int_{0}^{\infty} e^{-y} y^{3} d y=6\right|=\int_{0}^{F} \frac{6 x d x}{(x+1)^{4}} .
\end{aligned}
$$

Отже, маємо щільність $F$ - розподілу, для $k_{1}=4$, та $k_{2}=4$ :

$$
g(x)=\frac{6 x}{(x+1)^{4}}
$$


Перевіримо

відповідність загальній формулі розподілу Фішераотриманих результатів (9)-(10) Снедекора:

$$
f(x)=\frac{\Gamma\left(\frac{k_{1}+k_{2}}{2}\right) \cdot k_{1}^{\frac{k_{1}}{2}} \cdot k_{2}^{\frac{k_{2}}{2}}}{\Gamma\left(\frac{k_{1}}{2}\right) \cdot \Gamma\left(\frac{k_{2}}{2}\right)} \cdot x^{\frac{k_{1}}{2}-1} \cdot\left(k_{1} x+k_{2}\right)^{-\frac{k_{1}+k_{2}}{2}}
$$

Для цього підставимо у цей вираз значення ступенів вільності, а саме $k_{1}=3$, $k_{2}=4:$

$$
\begin{aligned}
& f(x)=\frac{\Gamma\left(\frac{3+4}{2}\right) \cdot 3^{\frac{3}{2}} \cdot 4^{\frac{4}{2}}}{\Gamma\left(\frac{3}{2}\right) \cdot \Gamma\left(\frac{4}{2}\right)} \cdot x^{\frac{3}{2}-1} \cdot(3 x+4)^{-\frac{3+4}{2}}=\frac{\Gamma\left(3+\frac{1}{2}\right) \cdot 3^{\frac{3}{2}} \cdot 4^{2}}{\Gamma\left(\frac{3}{2}\right) \cdot \Gamma(2)} \cdot x^{\frac{1}{2}} \cdot(3 x+4)^{-\frac{7}{2}}= \\
& =\frac{15 \sqrt{\pi} \cdot 3 \sqrt{3} \cdot 16 \cdot 2}{8 \sqrt{\pi}} \cdot x^{\frac{1}{2}} \cdot(3 x+4)^{-\frac{7}{2}}=180 \sqrt{3} \cdot x^{\frac{1}{2}} \cdot(3 x+4)^{-\frac{7}{2}} .
\end{aligned}
$$

Враховано, що $\Gamma\left(3+\frac{1}{2}\right)=\frac{15 \sqrt{\pi}}{8} ; \Gamma\left(\frac{3}{2}\right)=\frac{\sqrt{\pi}}{2} ; \Gamma(2)=1$.

Тоді $g(x)=\frac{180 \sqrt{3 x}}{\frac{7}{2}}$, а для $k_{1}=4, k_{2}=4$ маємо:

$$
\begin{aligned}
& (3 x+4)^{\frac{7}{2}} \\
& f(x)=\frac{\Gamma\left(\frac{4+4}{2}\right) \cdot 4^{\frac{4}{2}} \cdot 4^{\frac{4}{2}}}{\Gamma\left(\frac{4}{2}\right) \cdot \Gamma\left(\frac{4}{2}\right)} \cdot x^{\frac{4}{2}-1} \cdot(4 x+4)^{-\frac{4+4}{2}}=\frac{\Gamma(4) \cdot 4^{2} \cdot 4^{2}}{\Gamma(2) \cdot \Gamma(2)} \cdot x \cdot \frac{(x+1)^{-4}}{4^{4}}= \\
& =6 \cdot x \cdot(x+1)^{-4} .
\end{aligned}
$$

Отже, $g(x)=6 x(x+1)^{-4}$ (враховано, що $\left.\Gamma(4)=6 ; \Gamma(2)=1\right)$.

Для обох розглянутих прикладів розподілу функції випадкової маємо повну відповідність результатів величини, задачі знаходження обчислень.

Отже, використавши базові поняття функції випадкового аргументу та згортку двох розподілів таких функцій, можна послідовно обчислювати значення основних статистичних функцій для будь-яких значень ступенів вільності.

Висновки. У роботі були досліджені алгоритми розв'язання наступних задач 3 курсу «Математична статистика»: задачі знаходження щільності та функції щільності та функції розподілу функції суми або частки двох випадкових величин. Ці задачі основані на відомих для здобувачів правилах диференціювання та інтегрування неперервних функцій.

Встановлено, що відомі алгоритми розв'язання перелічених задач потребують спрощення і вдоюконалення, оскільки, використовуючи відомий здобувачем базовий математичний апарат, нескладно показати алгоритми отримання виразів 
цих статистичних функцій у ряді простих випадків для невеликих ступенів вільності та порівняти результати цих обчислень із результатами, отриманими від загальних виразів на прикладі задачі знаходження розподілів $\chi 2$ та Ст'юдента для довільних ступенів вільностей.

Основна ідея спрощення цих алгоритмів полягає у послідовному знаходженні результатів від довільних ступенів вільності за допомогою отримання рекурентних залежностей. Для iii реалізації отримано прості i зручні алгоритми розрахунку базових статистичних функцій, використання яких розширює список вправ та задач розділу математичної статистики «Функції випадкового аргументу», які можна застосувати у освітньому процесі.
Доведено, що використавши базові понятяя функції випадкового аргументу та згортки двох розподілів таких функцій, можна послідовно обчислювати значення основних статистичних функцій для довільних значень ступенів вільності. Це заповнюе прогалину у освітньому процесі між базовими початковими означеннями та складними формулами статистичних функцій, пов'язаних с гамма-функцією Ейлера.

Передбачається ознайомлення здобувачів із узагальнюючими алгоритмами отримання базових статистичних функцій розподілу випадкових величин, які вибирає дослідник відповідно до виду альтернативної гіпотези, для кращому розумінню ними математичного апарату статистики.

\section{Список використаної літератури}

1. Опря А.Т. Наукові та освітньо-організаційні проблемні аспекти статистики. Вісник Полтавської державної аграрної академії, 2008. №4. С. 177-180.

2. Акопян К. А., Оганесян А. М. Современные проблемы статистического образования. Системное управление, 2016. Вип. 1 (30). URL: http://sisupr.mrsu.ru/2016-2/PDF/Hakobyan.pdf

3. Омельяненко В. А. Використання інноваційних технологій в процесі вивчення економіко-статистичних дисциплін. Траектория науки. Международный электронный научный журнал, 2017. № 1 (3). С. 2.1-2.11. URL: www.pathofscience.org

4. Яцкив И. В. Прикладная статистика: методы и проблемы в обучении. Computer Modelling \& New Technologies. Transport and Telecommunication Institute, 2001. No. 1 (5). P. 96-99.

5. Айвазян С. А., Мхитарян В. С. Прикладная статистика и основы эконометрики. Учебник для вузов. Юнити, Москва, 1998. 1022 с. 
6. Орлов А. И. Современная прикладная статистика. - URL: http://phisica.boom.ru/ pri /art5.html

7. Garfield J., Ben-Zvi D. Preparing school teachers to develop students' statistical reasoning. Teaching Statistics in School Mathematics-Challenges for Teaching and Teacher Education. A Joint ICMI/IASE Study: The 18th ICMI Study. Springer, 2008. P. 299-310.

8. Gordon S., Petocz P., Reid A. Teachers' Conceptions of Teaching Service Statistics Courses. International Journal for the Scholarship of Teaching and Learning, 2007.Vol. 1, No 1. P. 1-15. doi: 10.20429/ijsotl.2007.010110.

9. Gordon S. Understanding students' experiences of statistics in a service course. Statistics Education Research Journal, 2004. № 3 (1). P. 40-59. URL: http://iaseweb.org/documents/SERJ/SERJ3(1)_gordon.pdf

10. Sowey E. R. Letting students understand why statistics is worth studying. Proceedings of ICOTS-7, Seventh International Conference on Teaching Statistics / eds. A. Rossman, B. Chance, 2006. URL: http://www.stat.auckland.ac.nz/ iase/publications/ 17/3A1_SOWE.pdf

11. Helmert F.R. Über die Wahrscheinlichkeit von Potenzsummen der Beobachtungsfehler etc. Z. f. 1876. Math. U. Phys., 21, P. 102-219.

12. Pearson R. On the criterion that a given system of deviations from the probable in the case a correlated system of variables is such that is can be reasonably supposed to have arisen from random sampling. Phil. Mag. 1900. Vol. 50. P. 157-175.

13. Student. The probable error of a means. Biometrika. 1908. Vol. 6, No. 1, P. 1-25.

14. Fisher R.A. The distribution of the partial correlation coefficient. Metron. Vol. 3. 1924. P. 329-332.

15. Теория вероятности и математическая статистика / Н.Ш. Кремер и др. Москва: ЮНИТИ. Банки и биржи, 1997. 471 с.

16. Гмурман В.Е. Теория вероятностей и математическая статистика. Москва: Высш.шк., 1978. 479 с.

17. Барковский В.В., Барковська Н.В., Лопатін О.К. Математика для економістів: Теорія ймовірностей та математична статистика. Київ: Національна академія управління, 1997. 254 с.

18. Гнеденко Б.В. Курс теории вероятностей. Москва: Наука, 1969. 400 с. 